\title{
FORMAÇÃO DE PROFESSORES NA MODALIDADE A DISTÂNCIA: perfil dos egressos, permanência e saberes em um curso de Educação Física
}

\author{
Dennia Pasquali \\ Roberto Pereira Furtado ${ }^{2}$ \\ Ari Lazzarottti Filho3
}

\section{RESUMO}

Esse estudo buscou identificar o perfil dos estudantes que permaneceram no curso de licenciatura em Educação Física, na modalidade a distância, e os saberes significativos desenvolvidos nessa formação, relacionando-os com os motivos de permanência até o final do curso. O perfil dos estudantes foi analisado pelos dados disponibilizados pela secretaria do curso e, para analisar a formação em Educação Física, foi elaborado um grupo focal. Os estudantes que permaneceram (42,9\%) são na maioria mulheres $(52,9 \%)$; solteiros (51,9\%); a porcentagem de 85,7\% cursou a educação básica integralmente em escola pública; $88,4 \%$ possuem idade média de 35 anos e moram a uma distância média de $34 \mathrm{~km}$ do polo. Ficou de significativo dessa formação o letramento digital, os saberes pedagógicos desenvolvidos ao longo do curso e os saberes das práticas corporais, ao compreenderem a importância da Educação Física no processo de escolarização. Os motivos da permanência elencados foram a qualidade proporcionada pela universidade pública e aqueles de mérito individual como a persistência, a disciplina e a autonomia.

Palavras-chave: Formação de professores. Educação física. Educação a distância. Permanência

1 Mestre em Educação Física. Doutoranda em Educação Física na Universidade de Brasília (PPGEF/UNB). Brasília/ Distrito Federal, Brasil. E-mail: dennia_pasc@hotmail.com

2 Doutor em Educação. Professor da Universidade Federal de Goiás (UFG). Goiânia/Goiás, Brasil. E-mail: cremerroberto@hotmail.com

3 Doutor em Educação Física. Professor da Universidade Federal de Goiás (UFG). Goiânia/Goiás, Brasil. E-mail: arilazzarotti@gmail.com 
TEACHER EDUCATION IN DISTANCE EDUCATION: profile of the egress, stay and knowledge in a Physical Education course

\begin{abstract}
This study sought to identify the profile of the students who remained in the degree course in Physical Education, distance education, and the significant knowledge developed in this formation, relating them to the reasons for staying until the end of the course. The profile of the students was analyzed by the data provided by the course secretariat, and to analyze the formation in Physical Education, a focus group was elaborated. The students who remained (42.9\%) were mostly women $(52.9 \%)$; single students $(51.9 \%)$; $85.7 \%$ studied in basic education of public schools; $88.4 \%$ had an average age of 35 years and lived at a medium distance $34 \mathrm{~km}$ from the pole. The digital literacy, the pedagogical knowledge developed throughout the course and the knowledge of the corporal practices were understood as significant in understanding the importance of Physical Education in the schooling process. The reasons for stay listed were the quality provided by the public university and those of individual merit such as persistence, discipline and autonomy.
\end{abstract}

Keywords: Teacher education. Physical education. Distance education. Stay

FORMACIÓN DE PROFESORES EN EL MODO A DISTANCIA: perfil de los egresos, permanencia y saberes en un curso de Educación Física

\title{
RESUMEN
}

Este estudio buscó identificar el perfil de los estudiantes que permanecieron en el curso de licenciatura en Educación Física, en la modalidad a distancia, y los saberes significativos desarrollados en esa formación, relacionándolos con los motivos de permanencia hasta el final del curso. El perfil de los estudiantes fue analizado por los datos facilitados por la secretaría del curso y, para analizar la formación en Educación Física, se elaboró un grupo focal. Los estudiantes que permanecieron $(42,9 \%)$ son en su mayoría mujeres (52,9\%); solteros (51,9\%); el porcentaje de 85,7\% cursó la educación básica íntegramente en escuela pública; el 88,4\% tiene una edad media de 35 años y viven a una distancia media de $34 \mathrm{~km}$ del polo. Ha quedado de significativo en la formación el significado digital, los saberes pedagógicos desarrollados a lo largo del curso y los saberes de las prácticas corporales, al comprender la importancia de la Educación Física en el proceso de escolarización. Los motivos de la permanencia enumerados fueron la calidad proporcionada por la universidad pública y aquellos de mérito individual como la persistencia, la disciplina y la autonomía.

Palabras clave: Formación de profesores. Educación física. Educación a distancia. Quedarse 


\section{INTRODUÇÃO}

A modalidade de Educação ${ }^{4}$ a Distância $(E a D)$ tem crescido nos últimos anos no Brasil, alcançando só no ano de 2014, de acordo com o Censo da Educação a Distância ${ }^{5}$ (2014), o número de 1.840 cursos regulamentados totalmente a distância. Essa expansão denota que as experiências com EaD tem avançado, e por serem, em sua maioria, experiências novas, há muito ainda para se compreender visando sua consolidação (SANCHES, 2009).

Pelo fato da EaD estar em recente consolidação, Mill e Oliveira (2014) apontam que ainda é tênue a relação entre a EaD e o campo investigativo da pesquisa, se comparada a temas científicos mais consolidados. Dessa forma, há a necessidade de mais pesquisas em relação a este tema, porque ainda "há muito por compreender sobre esta modalidade, especialmente pelas novas condições, demandas e desafios postos pelos mais recentes avanços das tecnologias digitais de informação e comunicação" (MILL; OLIVEIRA, 2014, p. 16).

Tem sido objeto de estudos a evasão dos estudantes dos cursos dessa modalidade educacional, como os de Wilges et al. (2010) e de Martins et al. (2013). O Censo da Educação a Distância de 2014 (EAD.BR), aponta a evasão como um dos maiores obstáculos a serem enfrentados por cursos na modalidade a distância, apresentando como principais causas a falta de tempo de estudos por parte dos estudantes diante da conciliação entre estudos e trabalho, a falta de adaptação à metodologia da modalidade educacional, sobretudo em relação ao domínio técnico das tecnologias digitais e a pouca interação presencial com colegas e professores.

Em uma perspectiva antagônica, porém relacionada com a tentativa de minimizar os índices de evasão, estão os estudos de sucesso/permanência, como os de Fernandes et al (2013) e de Fiuza e Sarriera (2013), em que a permanência é entendida como a ação de continuidade de participação dos estudantes que leva à diplomação em um curso de graduação. Esses estudos apontam como motivos de permanência as características dos estudantes e das instituições formadoras, integração social e motivos pessoais como persistência. Também revelam a desistência como uma opção consciente e não como um fracasso escolar.

Para contribuir com os estudos de evasão e permanência na EaD e para compreender como ela se efetiva na $\mathrm{EF}$, a presente pesquisa teve como objetivo identificar o perfil dos estudantes que permaneceram no curso de licenciatura em Educação Física, na modalidade a distância, e os saberes significativos desenvolvidos nessa formação, relacionando-os com os motivos de permanência até o final do curso.

A EaD na EF a partir da primeira década desse século tem sido objeto de estudo por diferentes autores com distintos temas/objetos de estudo, os quais destacamos: o perfil dos estudantes (CRUVINEL; LAZZAROTTI; SILVA, 2011), a especificidade da EF

4 Os autores declaram não haver conflito de interesse pessoal, comercial, político, acadêmico ou financeiro neste artigo.

5 Informações disponíveis no site da Associação Brasileira de Educação a Distância (ABED): < http://www.abed. org.br/site/pt/>. Acesso em: 12 Jul. 2016. 
(LAZZAROTTI; SILVA; PIRES, 2013), (ALMEIDA, 2013) e (LAZZAROTTI FILHO et al, 2015), estágio supervisionado (QUARANTA E PIRES, 2013), e a mediação Pedagógica (SILVA, 2012), (AMARO, 2012) e (MELANI, 2013). Essas pesquisas vêm desvelando elementos dessa formação e constituindo uma preocupação científica com o fenômeno apresentado.

Para esse estudo, foram utilizadas as referências sobre os saberes docentes (TARDIFF, 2008) e mais especificamente, os saberes da formação, os quais são provenientes da formação profissional, no caso estudado, o curso de Licenciatura em EF, na modalidade EaD da Faculdade de Educação Física e Dança da Universidade Federal de Goiás (FEFD/ UFG). Esses saberes da formação se integram aos saberes pessoais dos professores, aos saberes provenientes da formação escolar anterior, aos saberes provenientes dos programas e livros didáticos usados em suas experiências profissionais e aos saberes provenientes de sua própria experiência com a profissão na sala de aula. Dessa forma, esses saberes funcionam como filtros e se integram na prática docente do professor.

\section{METODOLOGIA}

Esta pesquisa é caracterizada como um estudo de caso, e a obtenção dos dados para a análise ocorreu por meio de duas técnicas de coleta de dados: análise de documentos disponibilizados pela Coordenação do curso de Licenciatura em EF/EaD da FEFD/UFG, e um grupo focal (GATTI, 2012) com os estudantes, prováveis formandos, no final do ano de 2013.

Os documentos disponibilizados pela Coordenação do curso de EF/EaD/FEFD, como o Projeto Pedagógico de Curso (PPC) e a ficha com os dados dos estudantes foram analisados com a finalidade de identificar as características dos estudantes que permaneceram até o final do curso. Por meio destes, foi construída uma tabela no software Excel com as seguintes entradas: estudante; cidade polo; data de nascimento; residência atual; estado civil; cursou ensino médio (público, privado, maioria público ou maioria privado); tipo do ensino médio regular, educação profissional e tecnológica (EPT) ou educação de jovens e adultos (EJA).

O grupo focal é elucidado por Gatti (2012, p. 449) como "[...] um conjunto de pessoas selecionadas e reunidas por pesquisadores para discutir e comentar um tema, que é o objeto de pesquisa, a partir de sua experiência pessoal". Assim, essa técnica de coleta de dados teve a finalidade de perceber as relações entre os saberes e demais contribuições do processo formativo com a permanência do estudante no curso. A seleção para a composição do grupo focal foi feita através de sorteio, contemplando um estudante de cada polo ${ }^{6}$ do curso $\mathrm{EF} / \mathrm{EaD}$. Entretanto, dois estudantes não puderam comparecer ficando o grupo composto por 7 estudantes. Salienta-se que a pesquisa fora aprovada pelo Comitê de Ética em Pesquisa da Universidade Federal de Goiás sob o protocolo 157/2008, e que toda a seção do grupo focal foi gravada por meio de um gravador de voz e posteriormente, transcrita.

6 O curso de EF/EaD do programa UAB II teve 9 polos distribuídos pelo estado de Goiás, nas seguintes cidades: Alexânia, Cidade de Goiás, Formosa, Goianésia, Inhumas, Iporá, Mineiros, São Simão e Uruana. 
Após a transcrição das informações obtidas do grupo focal, foi empregado a técnica de análise de conteúdo (BARDIN, 2010) que consiste em sistematizar e descrever o conteúdo das mensagens obtidas e com o auxílio do programa Web Qualitative Data Analyses (WebQDA)7, e assim foram desenvolvidas as seguintes etapas: 1) Inserção da transcrição do grupo focal; 2) Realização da leitura flutuante onde se chegou nas 3 categorias (Quadro 1); 3) Realização da codificação buscando agrupar indícios nas falas do grupo focal às categorias correspondentes; 4) Individualização de cada categoria criando as subcategorias que agrupavam indícios de resposta aos objetivos da pesquisa; 5) Construção de inferências e busca de compreensão/resposta aos objetivos da pesquisa.

Quadro 1: Categorias do Grupo Focal e suas respectivas codificações

\begin{tabular}{|c|c|c|}
\hline Categoria & Subcategoria & $N^{0}$ codificações \\
\hline \multirow{2}{*}{ Contribuições da formação } & Letramento Digital (LD) & 17 \\
\hline & Inclusão Social (IS) & 12 \\
\hline \multirow{2}{*}{ Saberes } & Saberes Pedagógicos (SP) & 12 \\
\hline & Saberes das Práticas Corporais (SPC) & 07 \\
\hline Permanência & Mérito individual (MI) & 07 \\
\hline
\end{tabular}

Para a apresentação dos dados referentes a essa codificação foi usada a seguinte representação: Paulo LD1 - em que Paulo representa o nome fictício do sujeito participante do grupo focal, seguido pela inicial LD (Letramento Digital) que diz respeito a subcategoria dentro da categoria analisada e o número 1 que representa a respectiva codificação. As demais codificações seguiram a mesma lógica.

\section{Resultados e discussões}

Os dados serão apresentados seguindo o processo de análise em duas dimensões: Na primeira, será apresentado o perfil dos estudantes que ingressaram e os egressos no curso. Na segunda será feita a apresentação e discussão das três categorias analíticas: contribuições da formação, saberes da formação e a permanência, com as suas subcategorias.

\section{O perfil dos estudantes de Educação Física, modalidade a distância}

O curso de EF/EaD da FEFD/UFG iniciou no ano de 2009 com o ingresso de 316 estudantes, distribuídos por 9 polos no interior do estado de Goiás, como mostra a

7 O WebQDA é um sistema online de apoio à análise de dados qualitativos num ambiente colaborativo e distribuído (SOUZA; SOUZA e COSTA, 2014. Para saber mais, acessar: https://www.webqda.net/. 
Tabela 1. No ano de 2014, o quantitativo de 134 estudantes representa aqueles que permaneceram até o final do curso, sendo $42,4 \%$ do total de ingressos.

Dentre os estudantes que ingressaram no ano de 2008, 53,5\% eram do sexo masculino, como mostra a Tabela 1. No entanto, dos estudantes que permaneceram até o final do curso, 52,9\% eram do sexo feminino, o que demonstra uma permanência maior de mulheres na finalização do curso.

Esses dados apresentam similaridade com os do Censo da Educação a Distância no ano de 2010, que foi o primeiro censo no país e que mais se aproxima ao ano de ingresso dos estudantes do curso EF/EaD, e o Censo EAD.BR de 2014. Segundo o Censo EAD.BR de 2010, o Centro Oeste era a região com maior porcentagem de homens (53\%) matriculados em cursos na modalidade a distância, diferentemente das demais regiões do país, em que o predomínio em cursos nessa modalidade educacional era de mulheres. Já o Censo EAD.BR de 2014 mostra que nos cursos totalmente a distância, mais da metade dos estudantes são mulheres.

Tabela 1: Diferenças entre os estudantes que ingressaram e os estudantes egressos

\begin{tabular}{|c|c|c|c|c|c|c|c|c|}
\hline & \multicolumn{4}{|c|}{ Gênero } & \multirow{3}{*}{$\begin{array}{l}\text { Idade } \\
\text { média } \\
\text { (anos) }\end{array}$} & \multirow{3}{*}{$\begin{array}{c}\text { Distância } \\
\text { média }(\mathbf{k m}) \\
\text { casa/polo }\end{array}$} & \multicolumn{2}{|c|}{ Total } \\
\hline & \multicolumn{2}{|c|}{ Masc } & \multicolumn{2}{|c|}{ Fem } & & & $\Delta$ & 0 \\
\hline & $\mathbf{N}$ & $\%$ & $\mathbf{N}$ & $\%$ & & & N & $\%$ \\
\hline $\begin{array}{l}\text { Estudantes ao } \\
\text { ingressarem }\end{array}$ & 169 & 53,5 & 143 & 45,2 & 33 & 30,83 & 316 & 100 \\
\hline $\begin{array}{l}\text { Estudantes } \\
\text { egressos }\end{array}$ & 62 & 46,26 & 72 & 53,73 & 35 & 34 & 134 & 42,4 \\
\hline
\end{tabular}

Em relação à idade média dos estudantes, observa-se que era de 33 anos ao ingressarem no curso e, no final, a média de idade subiu para 35 anos $^{8}$, indicando aumento de 2 anos. Ao estratificarmos a faixa etária dos estudantes egressos identificou-se que 47,76\% tinham faixa etária entre 30 a 39 anos. Tal ocorrência pode ser explicada pelo fato dos estudantes mais novos terem outras oportunidades de estudo ou pelo fato de não terem as características desenvolvidas para essa modalidade como autonomia e disciplina para o estudo à distância, como aponta Belloni (2003).

A relação entre a distância da casa do estudante ao polo e à sede do curso está em discussão no sistema UAB. Alguns gestores, diretamente ligados ao programa, apontam uma relação direta de desistência dos estudantes quando estes estão em distâncias maiores dos polos. Uma distância geográfica maior dificulta o acompanhamento e o deslocamento para as aulas presenciais e atividades de apoio desenvolvidas. Existem instituições que já estão estabelecendo um raio de 100 km de distância como limite máximo para o estudante ingressar nos cursos.

8 A média de idade, tanto dos estudantes que entraram como dos egressos, foi realizada no ano de 2014 através de tabela dinâmica, assim os 4 anos do curso não interferiu para identificar a idade média da entrada e saída. 
Na realidade pesquisada, os estudantes que ingressaram tinham uma distância média de 30,83 km, já os que permaneceram apresentam uma distância de 34 km, isto é, não foi identificado mudança significativa com relação à distância média do Polo dos estudantes egressos, dado este também confirmado com o Censo EAD.BR (2014).

Os estudantes do curso de EF/EaD estavam vinculados a um dos 9 Polos situados no interior do Estado de Goiás, entretanto seus estados e municípios de origem não necessariamente eram desses polos. Os estudantes eram oriundos de 45 municípios do Estado de Goiás e 2 municípios do Distrito Federal. Reitera-se que o curso de EF/EaD atingiu o número significativo de 18,29\% de municípios do interior do Estado de Goiás que tiveram pelo menos um profissional formado em EF. Na Figura 1, é possível identificar como foi a distribuição geográfica e a quantidade dos estudantes formados por município.

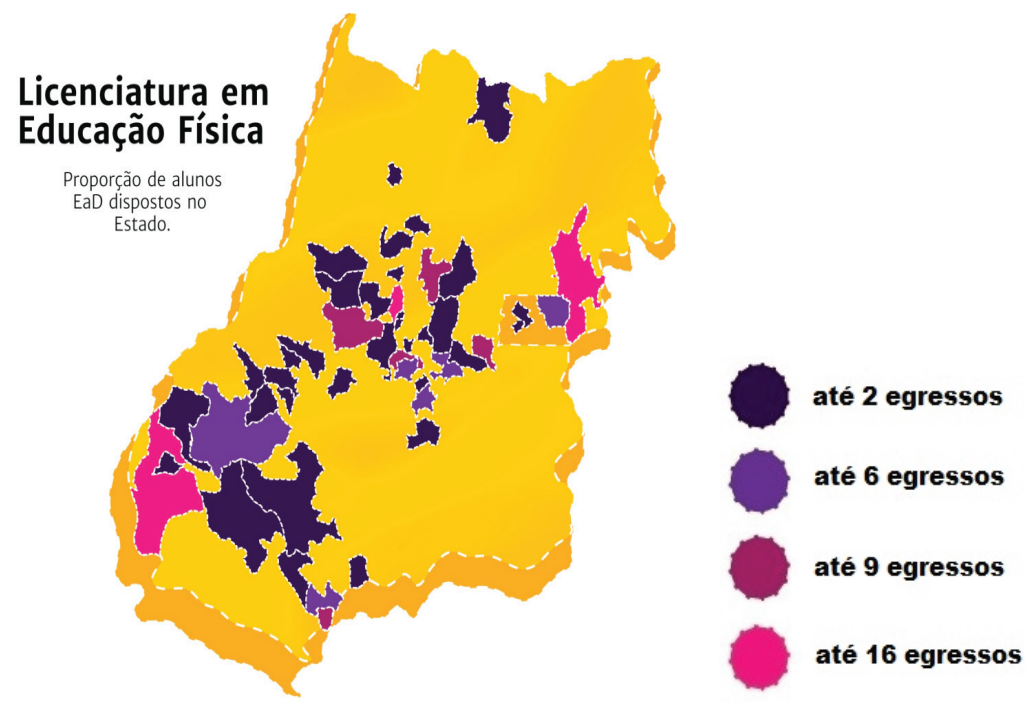

Figura 1: Disposição dos estudantes que permaneceram no curso de EF/EaD por município em Goiás

Ao analisarmos o tipo de escola e o tipo de ensino médio cursado pelos estudantes que permaneceram no curso foi possível inferir que a maioria $(\mathrm{N}=114) 85,7 \%$ frequentou a escola pública integralmente e $(\mathrm{N}=14) 10,44 \%$ cursou parcialmente em escola privada. Ao estratificarmos o Ensino Médio dos estudantes que permaneceram, na tabela 2, é possível identificar que a maioria estudou no Ensino Médio Regular ( $\mathrm{N}=81$ ) 60,44\%, Educação Profissional Técnica (EPT) $(\mathrm{N}=21)$ 15,67\%, Magistério ( $N=18), 13 \%$ e Educação de Jovens e Adultos (EJA)/Supletivo ( $N=14), 10,1 \%$. Destaca-se que 10,1\% dos estudantes que permaneceram desenvolveram os seus estudos no ensino médio em cursos de jovens e adultos e supletivo, cursos desenvolvidos para estudantes que não frequentaram a educação básica no seu tempo e sim depois de adultos. 
maio/2018

Tabela 2: Ensino Médio cursado pelos estudantes

\begin{tabular}{ccccccccc}
\hline & \multicolumn{2}{c}{ Regular } & \multicolumn{2}{c}{ EPT } & \multicolumn{2}{c}{ Magistério } & \multicolumn{2}{c}{ EJA/supletivo } \\
\cline { 2 - 8 } & N. & $\%$ & N. & $\%$ & N. & $\%$ & N. & $\%$ \\
\hline $\begin{array}{c}\text { Estudantes } \\
\text { egressos }\end{array}$ & 81 & 60,44 & 21 & 15,67 & 18 & 13 & 14 & 10,1 \\
\hline
\end{tabular}

Para concluir essa dimensão podemos afirmar que permaneceram no curso 134 $(42,45 \%)$ estudantes, sendo desses, a maioria mulheres $(52,9 \%)$, com idade média de 35 anos, solteiros $51,9 \%$, que cursaram o ensino médio regular $60 \%$, integralmente em escola pública $88,4 \%$ e que moravam a uma distância média da cidade-polo de $34 \mathrm{~km}$.

Vale destacar que esse percentual de $42,45 \%$ torna-se significativo na medida em que é a primeira experiência dessa modalidade educacional na instituição estudada, assim como deve ser levado em consideração a própria especificidade e natureza do campo da EF (LAZZAROTTI FILHO; SILVA; PIRES, 2013). No entanto, essa porcentagem está abaixo do que é apresentado pelo Censo EAD.BR (2014) que possui índices mínimos de pelo menos $50 \%$ de permanência dos estudantes em cursos totalmente a distância das instituições pesquisadas.

Diante dos dados apresentados, apontamos a seguir alguns motivos que levaram os estudantes a permaneceram até o final do curso de $\mathrm{EF} / \mathrm{EaD}$, bem como o que de significativo ficou para esse grupo de estudantes, no intuito de trazer elementos que possam auxiliar o campo acadêmico-científico nas discussões sobre evasão e permanência na graduação em EF, e para auxiliar na gestão de novos cursos, na modalidade a distância.

\section{A formação em Educação Física, modalidade a distância}

Dentre as contribuições significativas que o curso EaD/FEFD teve para os estudantes, dois aspectos foram identificados no grupo focal: o letramento digital devido ao contato com computador, internet e outras tecnologias, e a inserção social proporcionada aos sujeitos, em âmbitos pessoais de relacionamento com seus pares, bem como do prestígio que uma instituição federal de ensino superior representa socialmente. Já dentre os saberes da formação, os estudantes identificaram os saberes pedagógicos e os saberes com as práticas corporais. Quanto ao motivo da permanência, os estudantes afirmam que é mérito individual pelas suas características de autonomia, disciplina e busca dos objetivos.

\section{Contribuições do curso para os estudantes}

Por se tratar de curso de EF, na modalidade a distância, o uso de tecnologias de informação e comunicação, como o computador e a internet para o desenvolvimento das 
atividades, acesso aos fóruns de discussões, envio de atividades, contato com hipermídia, hipertexto, dentre outros, são considerados essenciais para o processo de aprendizagem.

Destarte, o letramento digital foi identificado como um elemento de significativo valor para a formação dos estudantes. Diante das 17 codificações oriundas do grupo focal foi possível identificar que são apresentadas questões técnicas de acesso e domínio do computador, e das mídias, sobretudo o Modular Objetct-Oriented Dynamic Learning Environment (Moodle) ${ }^{9}$, que foi o ambiente virtual de aprendizagem usado no desenvolvimento de todas as disciplinas.

[...] A plataforma foi bem elaborada com certeza, dá essa dinâmica para a gente pode interagir com os colegas, com os professores, com formador, com o orientador, e eu também imaginava que seria algo mais limitado no início, mas até a questão dos professores postarem vídeos aulas na plataforma isso facilitou muito, disciplinas mais difíceis como Anatomia e Biomecânica [...] as vídeos aulas facilitaram (Carolina LD4).

O letramento digital é entendido por Pereira (2008) como o conjunto de conhecimentos que permite aos agentes envolvidos participarem das práticas letradas mediadas por computadores no mundo contemporâneo. Não se trata de um conhecimento técnico para a realização de tarefas com utilização do computador, e sim do seu sentido mais ampliado, deve extrapolar os limites da página e construir sentidos com a interação social.

Aspecto também presente no letramento digital como possibilidade de entender o potencial das mídias e ainda a necessidade do curso em explorar mais intensamente os recursos com finalidades de facilitar o aprendizado, como pode ser percebido na fala de um dos estudantes.

Eu acho que com o vídeo se os professores tivessem utilizados mais vídeos pra ele explorar.... o texto e passasse pra gente os pontos importantes do texto que era interessante a gente ver também nos vídeos uma aula expositiva, eu acho que seria bem interessante. Poucas disciplinas que eu tive utilizou vídeo aula na verdade (Abelardo LD10).

A inclusão social foi codificada 12 vezes. Os participantes do grupo focal entendiam que formar em um curso superior é uma forma de inclusão social, pois a maioria não teve esta oportunidade quando mais jovens, seja pela distância das suas residências com as instituições de ensino superior, seja pela necessidade de abandono dos estudos para se dedicarem exclusivamente ao trabalho.

Eu desde a minha adolescência meu sonho era cursar uma faculdade de Educação Física, mas na minha cidade não tinha, eu tive que me mudar para outra cidade, fiquei um bom tempo sem estudar, quando tive a oportunidade pela EAD corri atrás (João IS6).

9 O Moodle trata-se de um ambiente virtual de aprendizagem. Possui código aberto e utilizado como base da Universidade Aberta do Brasil para o desenvolvimento da educação a distância. 
O Censo EAD.BR (2014) identificou que a maioria dos estudantes matriculados em cursos totalmente a distância conciliavam estudos e trabalho, chegando a superar o percentual de $75 \%$ dos casos nas instituições pesquisadas.

Outro aspecto relevante para os estudantes é a oportunidade de vivenciar os estudos dentro de uma universidade federal, motivo este aparentemente distante para a maioria, só concretizado devido ao curso EF/EaD.

No meu caso, estar dentro de uma Universidade Federal acho que faz um pouco de diferença para mim, talvez fosse uma das poucas oportunidades. (Abelardo IS7).

Foi identificado que frequentar um curso superior público na modalidade a distância tornou-se atraente pelos aspectos econômicos, isto é, por ser gratuito, e pelo aspecto da locomoção, devido aos poucos encontros presenciais existentes, o que ofereceu aos estudantes a permanência na localidade em que moravam, sem que fossem empregados muitos gastos com transporte. Estes aspectos estão em consonância com os estudos de Fiuza e Sarriera (2013), que também apresentaram a gratuidade do ensino público e o prestígio social de uma universidade pública como elementos que possibilitam a permanência de estudantes em cursos de graduação.

A inclusão social também foi identificada na possibilidade da interação social com os demais estudantes de polos distintos, constituída através da relação de pertencimento com a própria turma e com a profissão, pois mesmo sendo um curso à distância houve relações interpessoais significativas que marcaram e ficaram na formação desses estudantes, como pode ser notado na fala abaixo:

\footnotetext{
Até quando a gente entrou no curso, a gente pensou que ia ficar isolado, não iria fazer essa amizade. Por exemplo, o nosso grupo lá de Formosa a gente quase que faz um presencial, assim a amizade é tão grande, a gente já fez vários churrascos na casa um do outro, a gente já fez trabalhos e assim a gente tem uma amizade muito boa, que não parece que o curso foi feito a distância, parece que foi feito no presencial. (Abelardo IS12).
}

Na modalidade a distância, a interação social é constituída devido aos momentos presenciais de ensino-aprendizagem, o que gera maior proximidade entre os estudantes, entre estudantes e tutores, estudantes e professores, bem como entre estudantes e gestores.

Assim, é possível entender o letramento digital, a gratuidade e o reconhecimento da universidade pública, e a inserção social, proporcionada no curso EF/EaD, como aspectos importantes da formação em EF, que contribuíram para que os estudantes permanecessem até o final do curso.

\section{Saberes pedagógicos e saberes das práticas corporais}

O conjunto dos saberes é utilizado pelos professores em todas as suas tarefas cotidianas de trabalho docente. Esses saberes são heterogêneos e oriundos de diversas fontes, 
e assim, o trabalho do professor é constituído da sua formação cultural, dos seus saberes escolares, dos saberes didáticos e pedagógicos constituídos na formação universitária e são, por fim, norteados de acordo com as normas curriculares vindos de programas de ensino (TARDIF, 2008).

A princípio, no que diz respeito aos saberes pedagógicos, o conjunto de estudantes participantes da pesquisa apontaram estes como significativos para a formação nessa modalidade educacional, a princípio pelo entendimento do que venha a ser a importância do professor na escola, desde o planejamento com a seleção dos conteúdos até o processo de avaliação.

[...] o curso todo foi voltado para a escola, para o olhar a escola, que era uma preocupação que eu não tinha quanto alguém que gostava da área de EF. Então o curso direcionou muito bem, ele não teve rodeios, 'nós estamos preparando vocês para atuar na escola, isso ficou de significativo pra mim' (Abelardo SP6).

Eu tinha uma visão do professor de EF, que ele chagava lá e dava a bola, aí o aluno jogava a bola e tudo bem. Não, a gente precisa planejar uma aula, para que tudo ocorra perfeitamente e na maioria das vezes, a gente perde uma noite de sono planejando a aula e tem que sair perfeita essa aula e eu não tinha essa visão do professor de EF. Hoje não, hoje eu sei que o professor tem que planejar a aula tem que sair perfeita, tem que ter o plano A e o plano B [...] (Natália SP7).

A dimensão dos saberes parte do pressuposto de que o professor não é apenas um reprodutor de conteúdos já existentes, mas sim, um sujeito que constituiu determinados conhecimentos em sua formação e ao longo de sua vida, e assim necessita transformá-los em conteúdos didáticos.

Os saberes das práticas corporais (LAZZAROTTI; SILVA; PIRES, 2013) são identificados como aqueles advindos das experiências com essas práticas ao longo da vida. Na pesquisa de Cruvinel; Lazzarotti e Silva (2011) foi identificado que esses saberes foram importantes e determinantes para a escolha do curso. Nesse trabalho foi possível confirmar tal importância e a maneira como isso transcorreu ao longo da formação.

[...] joguei futebol profissional pelo time da nossa cidade que disputa campeonato brasiliense metropolitano. Eu tinha uma escolinha de futebol com crianças, então eu era muito envolvido com o futebol de fato. Então essa minha ligação que fortaleceu essa minha vontade de continuar (Abelardo SPC1).

Eu participei de escolinha de Futsal, de Handebol, e fui sempre apaixonada por esporte, então eu queria estudar, aprofundar, levar a fundo aquilo do esporte. (Natália SPC5).

É possível identificar que os saberes advindos das experiências com as práticas corporais, para o conjunto de estudantes pesquisados, aparecem nas experiências fora do ambiente escolar, como em escolinhas de esportes, nas experiências advindas da EF escolar e pela influência do professor de EF quando eram alunos. 
Hoje eu sou professora de Educação Física em uma escola de educação infantil e eu vejo como as crianças gostam da aula de EF, como eles esperam o dia da aula de EF, eles ficam ansiosos, quando o professor chega à escola eles dizem «nossa professora você chegou, hoje é o nosso dia de aula de $\mathrm{EF}$ » eles ficam muito ansiosos com isso. Eu era assim quando criança, durante toda a minha formação eu sempre esperava pela aula de EF, era uma das aulas que eu mais gostava na escola. (Carolina SPC3).

A gente vê o professor de EF como o professor querido da Escola, e no meu caso não foi diferente era a professora que eu sempre me identifiquei com ela. Sempre gostei mais das aulas dela e desde muito cedo eu falava que eu seria professora de EF. (Carolina SPC2).

Tardif (2008) afirma que o professor deve legitimar sua área por si mesmo, mantendo-se atualizado sobre todos os componentes que fazem parte da sua profissão, inclusive fomentando discussões sobre a sua própria formação docente. Os saberes se materializam no ato de ensinar e são incorporados por múltiplas fontes como formação inicial e continuada, currículo e socialização escolar, conhecimento das disciplinas a serem ensinada, experiência na profissão, cultura pessoal e profissional, aprendizagem com os pares, etc.

Portanto, é possível perceber que para o conjunto de estudantes, que participaram da pesquisa, um conjunto de saberes foram primordiais para a formação profissional como professor, sendo identificados desde a escola do curso de EF até a mudança no modo de perceber a prática pedagógica.

\section{A permanência no curso de modalidade a distância}

As contribuições do curso e da formação que abrangem o letramento digital, inserção social e os saberes pedagógicos e das práticas corporais, bem como o perfil dos estudantes são determinantes que auxiliam na compreensão dos motivos pelos quais menos da metade - que equivale a 42,4\% (ver Tabela 1) - dos estudantes que começaram o curso de $\mathrm{EF} / \mathrm{EaD}$ conseguiram chegar até sua fase final.

Para melhor compreender a permanência é importante destacar também as lacunas da formação como uma das determinações da evasão. Assim, pelo grupo focal foram identificadas críticas ao curso, notadamente no que tange a falta de clareza das funções pedagógicas na organização curricular e sobre algumas disciplinas, por não realizarem essa função pedagógica, ao não apresentarem o feedback de trabalhos desenvolvidos por eles como avaliação.

Então... era estranho, porque não tinha um padrão, ou seja, uns tinha autonomia, falavam assim, manda para o meu e-mail a tarefa que eu vou considerar. Outros falavam assim, não tem que conversar com o professor formador, então quer dizer, essa nova pessoa do professor formador que não era tão presente na nossa vida, quem era presente era o professor orientador e ditava, vamos dizer assim, ele era o manda chuva, mas ele não era tão presente, a gente não tinha muito acesso (Abelardo SP8). 
Nota-se que alguns aspectos relacionados ao ensino presencial ainda são comumente associados no curso a distância. A relação entre professor e aluno, e principalmente as novas funções pedagógicas e novos agentes no processo como o orientador acadêmico, o tutor presencial e o professor formador aparecem como problemas no processo de ensino-aprendizagem. Outros determinantes podem ser elencados como desafiadores nos cursos a distância, tais como o uso adequado das mídias e do material didático e a clareza dos objetivos pedagógicos do curso (SANTOS; NETO, 2009).

Fatores pessoais, isto é, que dizem respeito à própria vida do estudante, também foram levados em consideração a fim de identificar possíveis causas da desistência, sendo os mais frequentes: a dificuldade de relacionar trabalho e estudos, os problemas familiares, as dificuldades com uso do computador e internet, aspectos que podem impossibilitar o desenvolvimento e acompanhamento das atividades pedagógicas.

Ainda com a finalidade de compreender o contrário da evasão, ou seja, a permanência dos estudantes foi sugerida aos integrantes do grupo focal que apontassem as características que determinaram a permanência dos mesmos até o final do curso. Dentre as principais características foram elencados a perseverança, a disciplina, a autonomia, elementos de cunho pessoal.

Eu sou perseverante. A grande maioria desistiu porque achou que seria muito fácil o curso a distância e aí a gente percebe que não é. Que é até mais difícil do que o presencial, que a gente tem que se virar, tem que correr atrás [...] temos que ser um pouco mais independente. (Jaqueline MI1).

Para mim também nesse caso foi perseverança e muita disciplina porque eu me vejo uma pessoa que eu gosto muito de correr atrás dos meus sonhos e um era cursar uma faculdade de Educação Física e a partir do momento que eu fui atrás e falei eu quero cursar e vou chegar até o fim. (William MI3).

Ajudou no nosso crescimento, porque a gente tem que correr atrás, é a valorização da nossa autonomia de você querer e conseguir por si mesmo sem esperar do outro. (Vanessa MI7).

O estudo a distância requer do acadêmico planejamento e organização para a escolha dos tempos e espaços para o processo de aprendizagem. Ao longo do curso, os estudantes são conduzidos a desenvolverem habilidades para a construção coletiva dos conhecimentos, de um comportamento mais autônomo de estudos e para busca de outros meios que possibilitem a aprendizagem, para além dos que já estão disponíveis na plataforma de ensino.

Os aspectos relacionados ao curso, como já apontados, e a proximidade dos estudantes com a especificidade da EF são apontadas como significativas para a permanência dos mesmos até o final do curso.

A persistência aliada às características do curso aparece com predominância quando se procura um motivo para a não desistência. Motivos de caráter pessoal que dizem respeito 
às próprias características de cada indivíduo, em conjunto com a carga social que uma instituição de ensino carrega, parecem ser determinantes no processo de permanência no curso pelo estudante de EF, modalidade a distância.

As características elencadas são similares aos encontrados por Fiuza e Sarriera (2013), em que a permanência é tida por questões pessoais (como motivação e persistência), questões acadêmicas (como a valoração da instituição) e questões contextuais que envolvem tanto o estudante quanto o curso.

Entretanto, a emergência da persistência e da perseverança como características pessoais relatadas como importantes para a permanência no curso revela que esse público possui condições de vida que não os permitem cursar a formação superior na modalidade a distância sem um elevado esforço pessoal. Tal aspecto indica que os esforços dos muitos que evadiram podem não ter sido suficientes para suas permanências diante das dificuldades enfrentadas pelo perfil de estudantes do curso em análise.

\section{CONCLUSÕES}

Esse trabalho buscou traçar o perfil dos estudantes que permaneceram até o final do curso de EF/EaD e os saberes desenvolvidos nessa formação, relacionando-os com os motivos de permanência dos estudantes até o final do curso. Nesse sentido, foi possível concluir que a maioria dos estudantes são mulheres, solteiras, que cursaram o ensino médio integralmente em escola pública, possuem idade média de 35 anos e moram a uma distância média do polo de 34 quilômetros.

Esse perfil foi comparado ao do grupo total de estudantes que ingressaram no curso, mostrando então, que ao final de 4 anos a média de idade dos que permaneceram foi maior. Em relação ao sexo, houve inversão do masculino que foi predominante entre aqueles que entraram no curso, para o feminino, o predominante entre os que permaneceram.

Destaca-se que foi significativo para esses estudantes o letramento digital na medida em que foram alfabetizados nas mídias digitais, e foram inseridos socialmente em uma universidade federal e em um curso superior já numa fase adulta, o que dificultaria sem a modalidade à distância. Esses aspectos também podem ser entendidos como importantes para a permanência dos estudantes, visto que distanciam das principais características que compõem os estudos de evasão como falta de domínio das tecnologias e falta de convívio com colegas e professores.

Também foi significativo no processo de formação os saberes pedagógicos constituídos ao longo do curso. Cabe destacar ainda que os saberes das práticas corporais em seus processos de escolarização da educação básica ou em outros espaços e os seus vínculos com essas práticas ao longo das suas vidas foi outro aspecto que contribuiu para a permanência destes estudantes.

As características pessoais dos estudantes concluintes como a persistência, a autonomia, e a disciplina, bem como outros fatores como a qualidade do curso e a identidade com as práticas corporais, podem ser indicadores dos motivos da permanência no curso 
de EF/EaD e das dificuldades para o desenvolvimento do curso que são postas pelas condições de vida deste público.

Aponta-se como limite do estudo um melhor delineamento no uso do software de análise de conteúdo assim como uma maior inserção de elementos analíticos em função de falta de outros estudos sobre o mesmo tema no campo da EF. Como sugestão aponta-se novos estudos sobre os campos de intervenção dos egressos dessa modalidade, no intuito de entender os limites de uma formação em EF, na modalidade a distância, para a intervenção profissional.

\section{REFERÊNCIAS}

ALMEIDA, Gunther Carlos Feitosa de. As mediações pedagógicas na formação docente a distância em educação física: uma análise das disciplinas que tratam das práticas corporais. 2013, 217 f. Dissertação (Mestrado em Educação) - Faculdade de Educação Física, Universidade de Brasília, Brasília, 2013.

AMARO, Rosana. Mediação Pedagógica online: análise das funções do tutor na Universidade Aberta do Brasil. 2012. 85 f. Dissertação (Mestrado em Educação) Faculdade de Educação, Universidade de Brasília, Brasília, 2012.

BARDIN, Laurence. Análise de conteúdo. Lisboa: Edições 70, 2010.

BELLONI, Maria Luiza. Educação a distância. 3 ed. Campinas, SP: Autores Associados, 2003.

CENSOEAD.BR. Relatório analítico da aprendizagem à distância no Brasil. São Paulo: Pearson Education do Brasil, 2010. Disponível em: http://www.abed.org.br/site/pt/ midiateca/censo_ead/1092/2013/03/censoead.br_2010/201 > . Acesso em: 18 Jan 2014.

CENSOEAD.BR. Relatório analítico da aprendizagem à distância no Brasil. São Paulo:

Pearson Education do Brasil, 2014. Disponível em: < http://www.abed.org.br/ censoead2014/CensoEAD2014_portugues.pdf>. Acesso em: 22 Ago 2016.

CRUVINEL, Fernanda; LAZZAROTTI FILHO; Ari, SILVA; Ana Márcia. Perfil do estudante da licenciatura em Educação Física da Universidade Federal de Goiás na modalidade à distância. Efdeportes, Revista Digital. Buenos Aires, ano 16, n.156, maio, 2011.

FERNANDES, Suzane Christine et al. Razões da persistência na graduação à distância: percepção dos alunos do curso de Licenciatura em Letras da UFPA, Polo Goianésia do Pará. In: X Congresso Brasileiro de Ensino Superior à Distância, 2013, Belém/PA. ESUD X Congresso Brasileiro de Ensino Superior à Distância: EaD rompendo fronteiras, 2013. Disponível em: <http://www.aedi.ufpa.br/esud/trabalhos/oral/AT5/114368. pdf $>$. Acesso em: 09 Ago 2016.

FIUZA; Patrícia Jantsch; SARRIERA, Jorge Castellá. Motivos para adesão e permanência na educação superior a distância. Psicologia: ciência e profissão. v.33, n.4. Brasília, 2013. Disponível em: <http://www.scielo.br/scielo.php?script=sci_arttext\&pid=S141498932013000400009\&lang =pt\#**a $>$. Acesso em: 27 Ago. 2016. 
GATTI, Bernadete Angelina. Grupo focal na pesquisa em ciências sociais e humanas. Brasília: Liber Livro Editora, 2012.

QUARANTA, André; PIRES, Giovani de Lorenzi. Histórias de vida e experiências docentes no estágio supervisionado de licenciandos em Educação Física - modalidade EAD. Movimento, 2013, 19(2), 185.

LAZZAROTTI FILHO, Ari et al. A dinâmica, os principais problemas e as qualidades no desenvolvimento de um curso de licenciatura em Educação Física na modalidade a distância. Pensar a prática, Goiânia, v. 18, n. 3, jul./set. 2015. Disponível em: < https:// www.revistas.ufg.br/fef/article/view/34504/19042 >. Acesso em: 08 Set. 2016.

LAZZAROTTI FILHO, Ari; SILVA, Ana Márcia; PIRES, Giovani. Saberes e práticas corporais na formação de professores de educação física na modalidade à Distância. Revista Brasileira de Ciências do Esporte, Florianópolis, SC, v. 35, n. 3, mai. 2013. Disponível em: < http://rbceonline.org.br/revista/index.php/RBCE/article/view/1316>. Acesso em: 02 Out. 2014.

MARTINS, Ronei Ximenes et al. (2013). Porque eles desistem? Estudo sobre a evasão de cursos de licenciatura a distância. In: Congresso Brasileiro de Ensino Superior, 10, 2013. Anais... Belém: UNIREDE, 2013. Disponível em: < http://repositorio.ufla.br/ bitstream/1/3127/1/EVENTO_Porque\%20eles\%20desistem.pdf $>$. Acesso em: 31 Ago. 2016.

MELANI, Nelma De Toni Donadelli Zonta. Tutoria na educação a distância: um estudo sobre a função pedagógica do tutor. 2013, 129 f. Dissertação (Mestrado em Educação) - Faculdade de Educação, Universidade de Brasília, Brasília, 2013.

MILL, Daniel; OLIVEIRA, Márcia Rozenfeld G. A educação a distância em pesquisas acadêmicas: uma análise bibliométrica em teses no campo educacional. Educar em Revista, Curitiba, Brasil, Edição Especial n. 5, p. 15 - 36. Editora UFPR, 2014.

PEREIRA, Gabriela Imbernom. Letramento Digital e professores de LE: Formação para o uso das novas tecnologias em salas de aula. Dissertação apresentada no Programa de Pós-graduação em Lingüística - Universidade Federal de São Carlos, 2008.

SANTOS, Elaine Maria dos; NETO, José Dutra de Oliveira. Evasão na educação à distância: identificando causas e propondo estratégias de prevenção. Revista Paidéi@ - Revista Científica de Educação a Distância. v.2, n.9. Dez, 2009. Disponível em: http:// revistapaideia.unimesvirtual.com.br/index.php?journal $=$ paideia\&page $=$ article $\&$ op $=$ view\&path \%5b\%5d=101\&path\%5b\%5d=96>. Acesso em: 05 Ago. 2016 .

SANCHES, Fábio. As estatísticas da EaD no Brasil. In: LITTO, F.; FORMIGA, M. (Org.). Educação à distância: $O$ estado da arte. São Paulo: Pearson Education, 2009. p. 445-455.

SILVA, Margarete Zambelli A mediação pedagógica no ambiente virtual de aprendizagem: análise dos fóruns do curso a distância de educação física. 2012. 97 f. Dissertação -PPGEF - Universidade de Brasília, Brasília, 2012.

SOUZA, Francislê Neri de; SOUZA, Dayse Neri de; COSTA, António Pedro. Importância do questionamento no processo de investigação qualitative. In: COSTA, António Pedro; SOUZA, Francislê Neri de; SOUZA, Dayse Neri de. (Org.). Investigação Qualitativa: inovação, dilemas e desafios. 2ed. Ludomedia, 2014. 
TARDIF, Maurice. Saberes Docentes e formação profissional. Petrópolis, RJ: Vozes, 2008. WILGES, Beatriz et al. Sistemas multiagentes: mapeando a evasão na educação a distância. RENOTE. Revista Novas Tecnologias na Educação, v. 8, p. 1, 2010.

Recebido em: Março/2017 Aprovado em: Setembro/2017 